This item was submitted to Loughborough's Research Repository by the author.

Items in Figshare are protected by copyright, with all rights reserved, unless otherwise indicated.

\title{
A bistable energy harvester for self-powered sensing in rail transport condition monitoring
}

PLEASE CITE THE PUBLISHED VERSION

https://doi.org/10.1109/Transducers50396.2021.9495492

PUBLISHER

IEEE

VERSION

AM (Accepted Manuscript)

\section{PUBLISHER STATEMENT}

Personal use of this material is permitted. Permission from IEEE must be obtained for all other uses, in any current or future media, including reprinting/republishing this material for advertising or promotional purposes, creating new collective works, for resale or redistribution to servers or lists, or reuse of any copyrighted component of this work in other works.

\section{LICENCE}

All Rights Reserved

\section{REPOSITORY RECORD}

Fu, Hailing, Yuan Zhang, Mengzhou Liu, Yong Qin, and Eric M. Yeatman. 2021. "A Bistable Energy Harvester for Self-powered Sensing in Rail Transport Condition Monitoring”. Loughborough University.

https://hdl.handle.net/2134/16776187.v1. 


\section{A BISTABLE ENERGY HARVESTER FOR SELF-POWERED SENSING IN RAIL TRANSPORT CONDITION MONITORING}

Hailing Fu ${ }^{1}$, Yuan Zhang ${ }^{2}$, Mengzhou Liu ${ }^{3}$, Yong Qin ${ }^{3}$ and Eric M. Yeatman ${ }^{4}$

${ }^{1}$ Wolfson School of Mechanical, Electrical and Manufacturing Engineering, Loughborough

University, Leicestershire, LE11 3TU, UK

${ }^{2}$ School of Mechanical Engineering, Beijing Institute of Graphic Communication, Beijing, China

${ }^{3}$ State Key Laboratory of Rail Traffic Control \& Safety, Beijing Jiaotong University, Beijing, China

${ }^{4}$ Department of Electrical and Electronic Engineering, Imperial College London, SW7 2AZ, UK

\begin{abstract}
A bistable vibration energy harvester for rail transport is proposed and developed to harness low-frequency train vibrations for self-powered condition monitoring. The operational vibration data collected from a train is analyzed to identify the design requirements. A free-sliding magnet is placed in a tube with two fixed magnets and limit springs to provide two stable positions for the movable magnet. This bistable behavior enhances the energy harvesting performance and operational bandwidth. A prototype was fabricated and tested using conditions similar to the real train operational conditions. A broad operation bandwidth $(20-40 \mathrm{~Hz})$ was obtained due to bi-stability. A peak output power of $1.1 \mathrm{~mW}$ was measured at $30 \mathrm{~Hz}$ and $6 \mathrm{~g}$ with a 600 $\Omega$ resistive load.
\end{abstract}

\section{KEYWORDS}

Energy harvesting; Bistability; Self-powered sensing; Rail transport; Condition morning.

\section{INTRODUCTION}

Rail transport is one of the major means of commuting and goods carriage. The safe and effective operation of rail transport is of great importance [1]. The development of wireless sensors and low-power electronics in the era of the Internet of Things provides solutions in long-term and continuous monitoring of rail vehicles and infrastructure in real time, which is key to enhancing traveler experience, maximizing the asset availability, and reducing operational costs $[2,3]$. However, issues such as reliable power supply for wireless sensors, data security, and system reliability, are still barriers for implementing such a monitoring system on a large scale.

Energy harvesting from vibration or motion has been investigated for over a decade to enable a self-powered solution for wireless sensing systems without replacing or recharging batteries [4]. Different mechanisms, including piezoelectric $[5,6]$, electrostatic $[7,8]$, triboelectric $[9,10]$ and electromagnetic transduction [11, 12], have been adopted in various applications, such as wearable devices, automotive, structural health monitoring, and wave energy generation $[13,14]$.

In rail transport, vibration is one of the usable energy sources for energy harvesting but exhibits unique features in dynamics, such as broad bandwidth and varying vibration amplitudes due to varying operational conditions. Designing a harvester with a broad operating bandwidth is one of the major challenges. Perpetuum commercialized one of the first energy harvesters for vibration-powered rail condition monitoring [15]. The lack of tight constraints on volume allows this device to generate enough energy for useful rail monitoring applications. Gao et al. developed a rail-borne energy harvester to harness the vibration induced by trains impacting on rail tracks [16]. Zhang et al. presented an energy harvester with a mechanical vibration rectifier to harness also railroad vibrations [17]. The system reliability of such energy harvesters using the rack-pinion mechanism is one of the concerns for long-term operation. $\mathrm{Fu}$ et al. developed a nonlinear energy harvester with coupled vibration modes to harness energy over a wide bandwidth; the harvester performance was examined under conditions similar to real operational conditions [18]. Although there have been various designs and devices presented in the literature, many challenges are still faced in terms of harnessing sufficient energy over a wide range within a miniaturized device.

In this work, bistability is introduced in a movable magnet concept combined with attractive magnetic force and limit springs. A compact system design is provided for effective energy harvesting.

\section{DESIGN AND OPERATIONAL PRINCIPLE}

To design a harvester tailored for real operating conditions, the on-site vibration data collected from a rail train were analyzed and presented in Fig. 1. As shown in
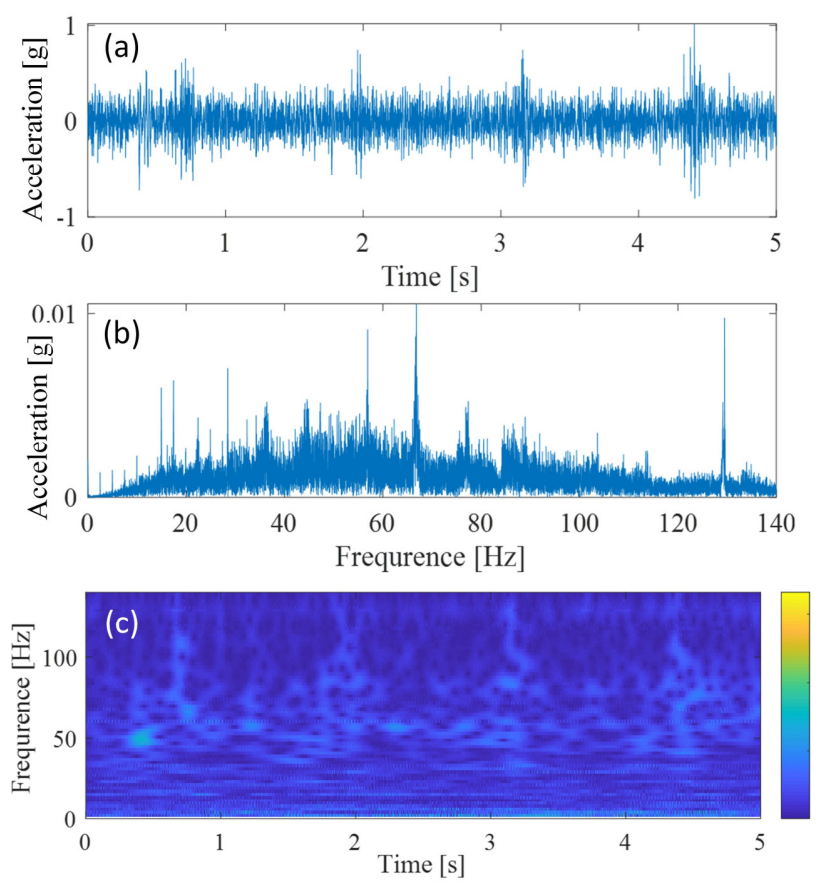

Figure 1: On-site vibration data collected from a running train. (a) acceleration in time; (b) frequency domain; (c) vibration frequency distribution in time-frequency domain. 
Fig. 1(a), the amplitude is below $1 \mathrm{~g}$; the frequency range is very broad from $20 \mathrm{~Hz}$ to $80 \mathrm{~Hz}$ (Fig. 1(b)), and the different frequency components are distributed over the whole time-domain. This means the harvester needs to exhibit wide operational bandwidth $(20-80 \mathrm{~Hz})$ and low excitation requirement $(<1 \mathrm{~g})$.

A bistable vibration energy harvester is proposed with simplicity and compactness in structure, as shown in Fig. 2. Two magnets are fixed at the ends of a circular tube. A movable magnet is placed inside the tube. The forces between magnets are attractive. In order to stop the moving magnet sticking on the fixed magnets, limit springs are introduced inside the tube, providing restoring forces for the movable magnet to oscillate inside the tube. Two stable positions are created by the combination of the restoring spring force and the attractive magnetic force, enhancing the energy harvesting performance over a wide frequency range. Two sets of coils are placed outside of the tube close to the stable positions. Holes are provided on the tube to reduce air damping when the moving magnet oscillates.

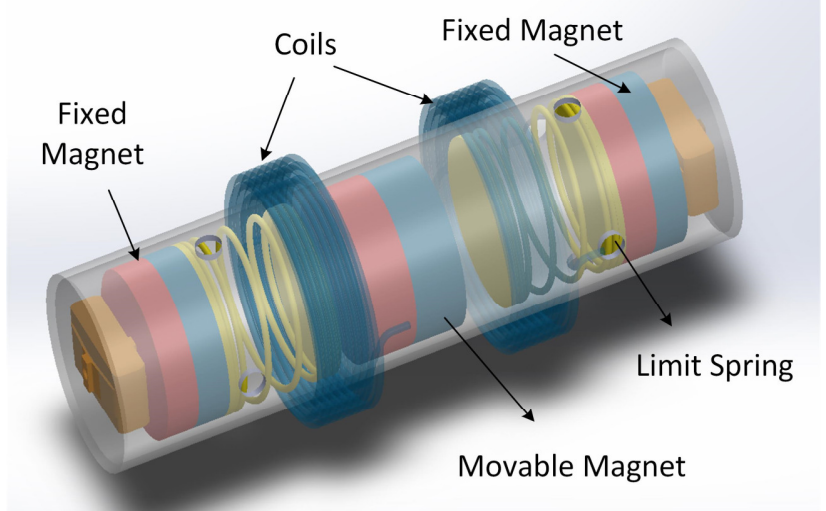

Figure 2: Schematic of a cm-scale bistable harvester using bi-stability and electromagnetic conversion.

The relationship between the spring restoring force and the magnetic forces is shown in Fig. 3. Before the movable magnet is in contact with the spring, only the magnetic force drives the movable magnet to either end of the tube. When the movable magnet compresses a limit spring, the spring restoring force increases sharply and surpasses the attractive magnetic force. Two stable positions are created by this magnet-spring configuration.

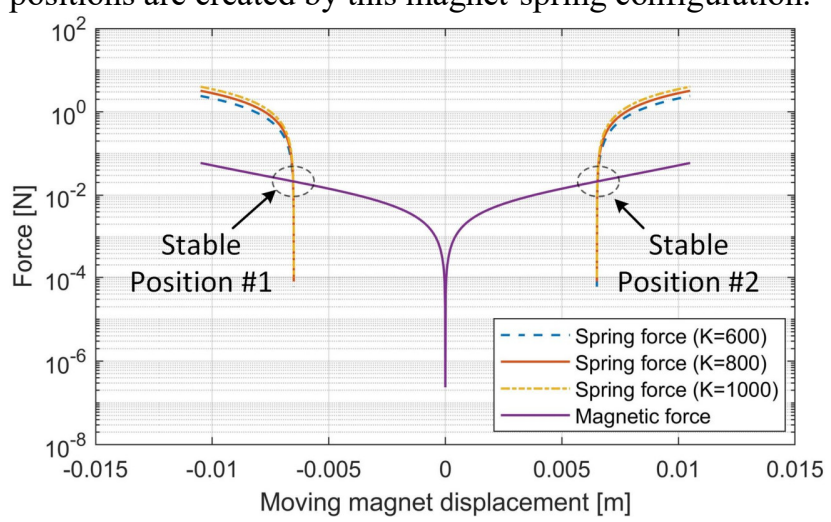

Figure 3: Magnetic and spring forces against moving magnet displacement, showing bi-stability creation.

The dynamics of the energy harvester are investigated by considering the magnetic force and spring restoring force, as shown in Fig. 4. When the excitation amplitude is low $(2 \mathrm{~g})$, the harvester operates in the intra-well mode with small amplitudes in displacement and velocity (Fig. 4(a)). When the excitation is enhanced, the inter-well oscillation is obtained with improved energy harvesting capability, as shown in Fig. 4(b). To allow the harvester to operate at low excitation amplitudes, the position of the limit spring can be adjusted to reduce the difficulty in realizing the interwell vibration.
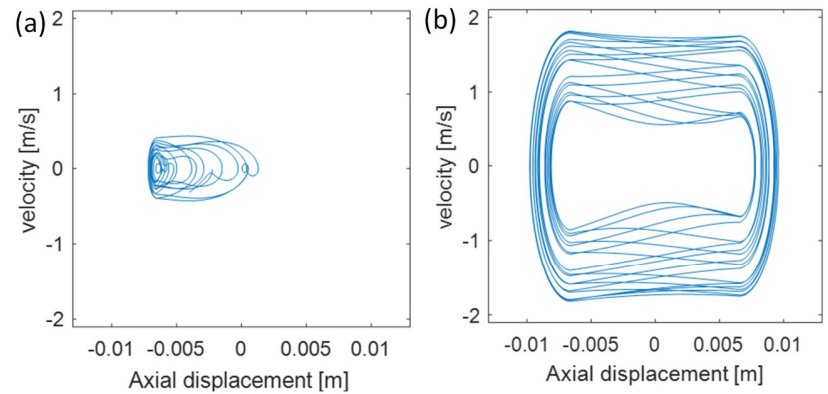

Figure 4: Simulation results for the harvester at different modes for different excitations at $30 \mathrm{~Hz}$. (a) $2 g$ and (b) $3 g$.

\section{PROTOTYPE \& EXPERIMENTAL SETUP}

The design is implemented as shown in Fig. 5. The overall dimensions are $\Phi 15 \times 50 \mathrm{~mm}$. The whole device was mounted on a shaker by a fixture. An accelerometer was used to record the input excitations. A signal generator (Keysight 33600A) and an amplifier (Shanghai Chengtec Electronics CO Ltd, CT5871) were used to drive the shaker (Shanghai Chengtec Electronics CO Ltd, JZK-2). Table 1 summarizes the materials and key parameters for different components of the prototype. The harvester was tested under different operational conditions.
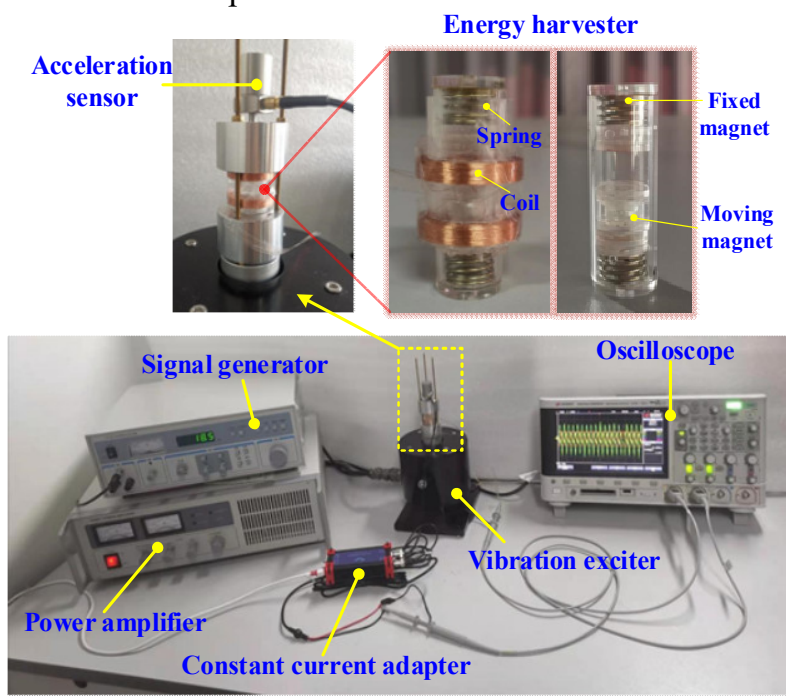

Figure 5: Harvester prototype and experimental setup.

Table 1. Energy harvester design parameters

\begin{tabular}{|c|c|c|c|}
\hline Part & Material & Parameter & Value \\
\hline \multirow{2}{*}{$\begin{array}{c}\text { Moving } \\
\text { magnet }\end{array}$} & NdFeB & Weight & $0.7 \mathrm{~g}$ \\
\cline { 3 - 4 } & $\mathrm{N} 38,1.2$ & Height & $5 \mathrm{~mm}$ \\
\cline { 3 - 4 } Fixed & NdFeB & Diameter & $5 \mathrm{~mm}$ \\
\cline { 3 - 4 } magnet & $(\mathrm{N} 38)$ & Diameter & $2 \mathrm{~mm}$ \\
\hline \multirow{2}{*}{ Spring } & \multirow{2}{*}{ Copper } & Height & $15 \mathrm{~mm}$ \\
\cline { 3 - 4 } & & Outer diameter & $5 \mathrm{~mm}$ \\
\hline
\end{tabular}




\begin{tabular}{|c|c|c|c|}
\hline & & Spring constant & $680 \mathrm{~N} / \mathrm{m}$ \\
\hline \multirow{4}{*}{ Coil } & \multirow{4}{*}{ Copper } & Height & $5 \mathrm{~mm}$ \\
\cline { 3 - 3 } & & Wire diameter & $0.08 \mathrm{~mm}$ \\
\cline { 3 - 3 } & & Inner diameter & $9 \mathrm{~mm}$ \\
\cline { 3 - 4 } & & Turns & 2500 \\
\cline { 3 - 4 } & & Resistance & $760 \Omega$ \\
\cline { 3 - 4 } Tube & \multirow{3}{*}{ Acrylic } & Inductance & $0.15 \mathrm{H}$ \\
\hline & & Height & $50 \mathrm{~mm}$ \\
\hline & & Inner diameter & $5 \mathrm{~mm}$ \\
\hline & & Outer diameter & $7 \mathrm{~mm}$ \\
\hline
\end{tabular}

\section{RESULTS AND DISCUSSIONS}

Fig. 6 shows the open-circuit voltage ( $3 \mathrm{~V}$ peak) of the harvester at $39 \mathrm{~Hz}$ and $6 \mathrm{~g}$. The harvester can effectively operate in the inter-well mode with improved output. High acceleration amplitudes are necessary for this prototype in order to maintain the high-energy orbit motion. From the output voltage curve, it can be seen that the oscillation frequency of the output voltage is 4 times higher than the excitation frequency. This is due to the sets of coils adopted in this design and the variation of the electromagnetic coupling coefficient.

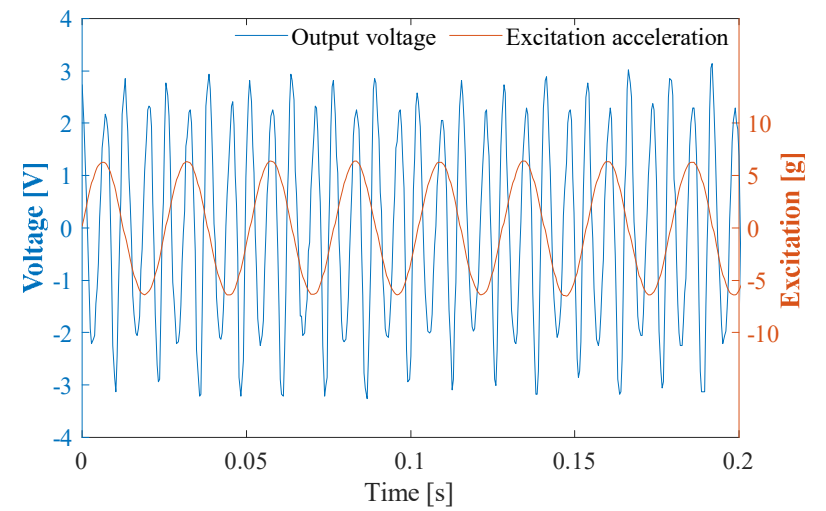

Figure 6: Open-circuit output voltage and input excitation against time (Excitation: $39 \mathrm{~Hz}$ and $6 \mathrm{~g}$ ).
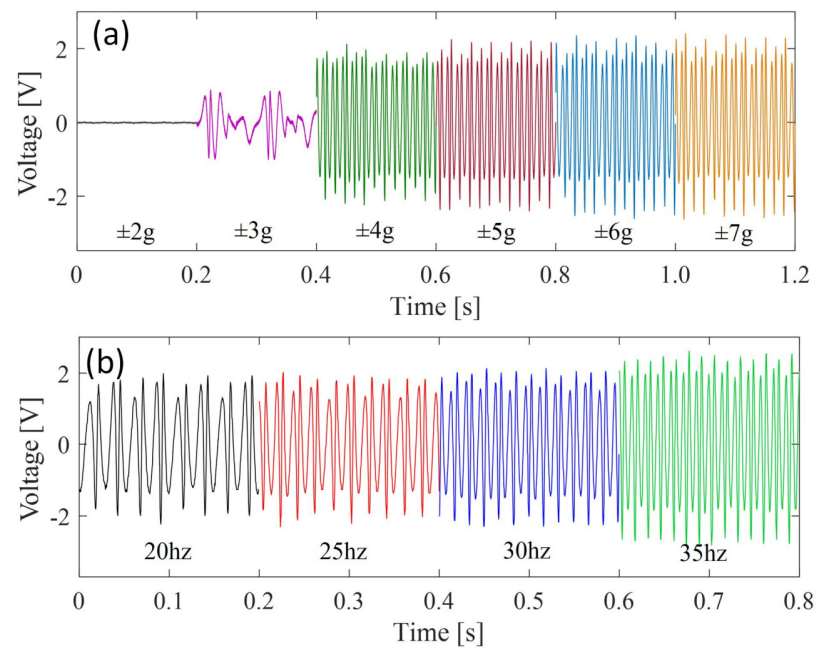

Figure 7: Output voltages at different excitations: (a) $2 \mathrm{~g}$ to $7 \mathrm{~g}$ at $30 \mathrm{~Hz}$; (b) $20 \mathrm{~Hz}$ to $35 \mathrm{~Hz}$ at $6 \mathrm{~g}$.

This required acceleration was examined further for the harvester operating in the double-well mode, as shown in Fig. 7. When the input excitation amplitude is lower than $4 \mathrm{~g}$, the device operates in the inter-well mode with marginal output voltage, as shown in Fig. 7(a). The output voltage increases to around $2 \mathrm{~V}$ when the input amplitude is above $4 \mathrm{~g}$. Reducing the friction between the movable magnet and the tube, and the attractive magnetic force are the potential solutions to allow the harvester to operate in the inter-well mode at lower excitation amplitudes. The wide operation bandwidth is shown in Fig. 7(b). The output voltage is stabilized at about $2 \mathrm{~V}$ from $20 \mathrm{~Hz}$ to $35 \mathrm{~Hz}$ with a slight increase.

In order to examine the output power under different load conditions, an impedance matching test was carried out, and the results are shown in Fig. 8. The input excitation was fixed at $30 \mathrm{~Hz}$ and $6 \mathrm{~g}$. The maximum output power is about $1.1 \mathrm{~mW}$ at $600 \Omega$

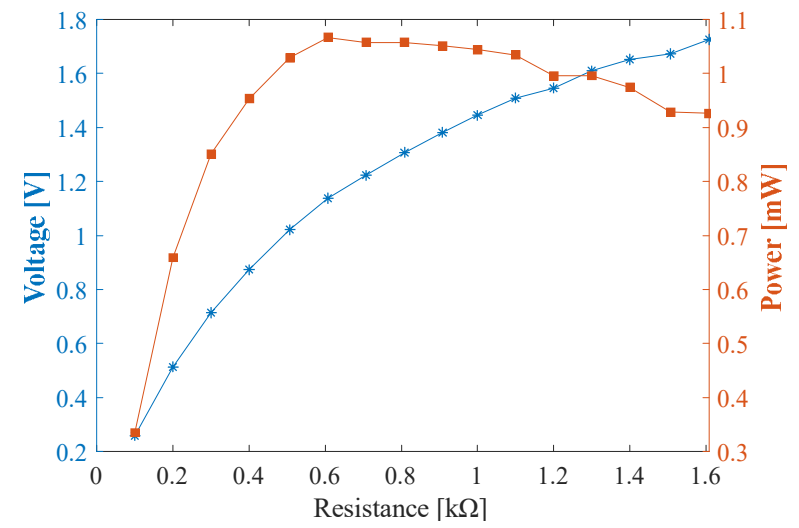

Figure 8: Impedance matching of the harvester (calculated using the peak output voltage) at $30 \mathrm{~Hz}$ and $6 g$.

In order to examine the bandwidth of the harvester, a frequency sweep test was conducted. The input excitation amplitude was fixed at $6 \mathrm{~g}$. Due to the nature of the shaker, the amplitude of the shaker cannot reach $6 \mathrm{~g}$ when the input excitation frequency is lower than $30 \mathrm{~Hz}$, as shown in Fig. 9(a). The harvester was stimulated in the frequency range from $10 \mathrm{~Hz}$ to $90 \mathrm{~Hz}$. The forward-sweep and reversesweep results are shown in Fig. 9(b). A wide operational frequency range is obtained (Forward: $18 \mathrm{~Hz}-40 \mathrm{~Hz}$ and backward: $15 \mathrm{~Hz}-32 \mathrm{~Hz}$ ). The issue for the current device is the high acceleration amplitude required to operate in the double-well mode. Reducing the friction and magnetic force on the movable magnet is the potential solution.
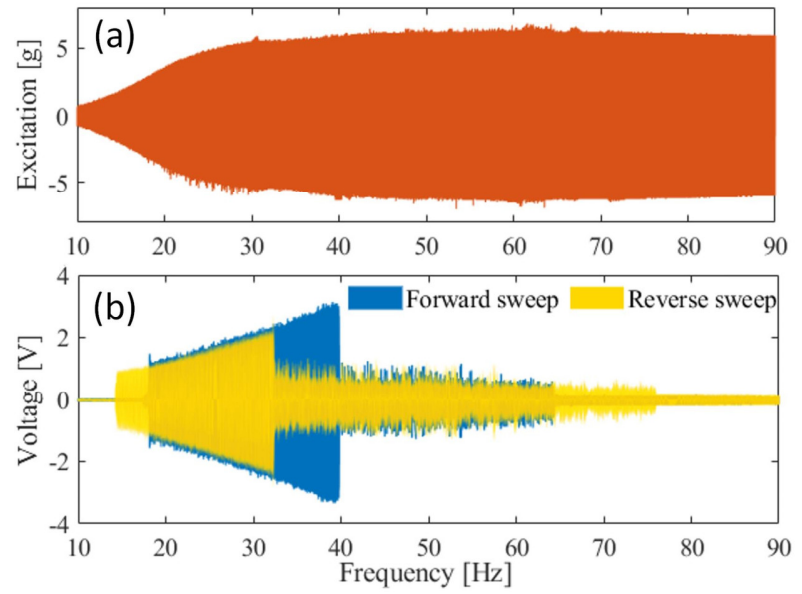

Figure 9: Experimental frequency sweep test of the energy harvester (acceleration at 6g, and sweep time is 200s). (a) input excitation and (b) Open-circuit voltage. 


\section{CONCLUSIONS AND FUTURE WORK}

A bistable energy harvester using a movable magnet combined with attractive magnetic forces and limit springs is developed in this work for harness broadband vibration energy from rail trains. The on-site operational data is first analyzed to identify the frequency range and excitation intensity. Based on these characteristics, the dynamics of the design are numerically studied, showing the bistable feature of the system. A prototype was fabricated and tested under different operational conditions. An output power of $1.1 \mathrm{~mW}$ was obtained at $600 \Omega$ at $30 \mathrm{~Hz}$ and $6 \mathrm{~g}$. A wide operational frequency range is illustrated (Forward: $18 \mathrm{~Hz}-$ $40 \mathrm{~Hz}$ and backward: $15 \mathrm{~Hz}-32 \mathrm{~Hz}$ ) in a frequency sweep test. The current challenge for this device is the high input excitation amplitude requirement in order for the harvester to operate in the double-well mode. Reducing the friction and attractive magnetic force is identified to be a potential solution to address this issue, which will be further studied in future work. Overall, this work provides a potential solution to harnessing rail transport kinetic energy over a wide bandwidth for self-powered sensing.

\section{ACKNOWLEDGEMENTS}

The authors would like to thank the support from the International Exchanges programme (IEC $\backslash N S F C \backslash 181655$ ) funded by the Royal Society, UK and the National Natural Science Foundation of China.

\section{REFERENCES}

[1] D. J. Graham, J. M. Carbo, R. J. Anderson, and P. Bansal, "Understanding the costs of urban rail transport operations," Transportation Research Part B: Methodological, vol. 138, pp. 292-316, 2020.

[2] Think beyond the rails: Leading in 2025 [Online]. Available: https://www.ibm.com/downloads/cas/XPEAAEY2.

[3] R. Melnik and S. Koziak, "Rail vehicle suspension condition monitoring-approach and implementation," Journal of Vibroengineering, vol. 19, no. 1, pp. 487$501,2017$.

[4] H. Liu, H. Fu, L. Sun, C. Lee, and E. M. Yeatman, "Hybrid energy harvesting technology: From materials, structural design, system integration to applications," Renewable and Sustainable Energy Reviews, p. 110473, 2020.

[5] H. Fu and E. M. Yeatman, "Rotational energy harvesting using bi-stability and frequency upconversion for low-power sensing applications: Theoretical modelling and experimental validation," Mechanical Systems and Signal Processing, vol. 125, pp. 229-244, 2019.

[6] J. Zhang and L. Qin, "A tunable frequency upconversion wideband piezoelectric vibration energy harvester for low-frequency variable environment using a novel impact-and rope-driven hybrid mechanism," Applied Energy, vol. 240, pp. 26-34, 2019.

[7] Y. Feng, B. Shao, X. Tang, Y. Han, T. Wu, and Y. Suzuki, "Improved capacitance model involving fringing effects for electret-based rotational energy harvesting devices," IEEE Transactions on Electron
Devices, vol. 65, no. 4, pp. 1597-1603, 2018.

[8] N. Miljkovic, D. J. Preston, R. Enright, and E. N. Wang, "Jumping-droplet electrostatic energy harvesting," Applied Physics Letters, vol. 105, no. 1, p. 013111, 2014.

[9] H. Zhang et al., "Employing a MEMS plasma switch for conditioning high-voltage kinetic energy harvesters," Nature communications, vol. 11, no. 1, pp. 1-10, 2020.

[10] J. Chen and Z. L. Wang, "Reviving vibration energy harvesting and self-powered sensing by a triboelectric nanogenerator," Joule, vol. 1, no. 3, pp. 480-521, 2017.

[11]H. Fu, S. Theodossiades, B. Gunn, I. Abdallah, and E. Chatzi, "Ultra-low frequency energy harvesting using bi-stability and rotary-translational motion in a magnet-tethered oscillator," Nonlinear Dynamics, vol. 101, no. 4, pp. 2131-2143, 2020.

[12]H. Liu et al., "A non-resonant rotational electromagnetic energy harvester for low-frequency and irregular human motion," Applied Physics Letters, vol. 113, no. 20, p. 203901, 2018.

[13] H. Wang, A. Jasim, and X. Chen, "Energy harvesting technologies in roadway and bridge for different applications-A comprehensive review," Applied energy, vol. 212, pp. 1083-1094, 2018.

[14]C. Wei and X. Jing, "A comprehensive review on vibration energy harvesting: Modelling and realization," Renewable and Sustainable Energy Reviews, vol. 74, pp. 1-18, 2017.

[15] S. Beeby and D. Zhu, "Vibration energy harvesting: fabrication, miniaturisation and applications," in Smart Sensors, Actuators, and MEMS VII; and Cyber Physical Systems, 2015, vol. 9517: International Society for Optics and Photonics, p. 951703.

[16] M. Gao, P. Wang, Y. Cao, R. Chen, and D. Cai, "Design and verification of a rail-borne energy harvester for powering wireless sensor networks in the railway industry," IEEE Transactions on Intelligent Transportation Systems, vol. 18, no. 6, pp. 1596-1609, 2016.

[17]X. Zhang, H. Pan, L. Qi, Z. Zhang, Y. Yuan, and Y. Liu, "A renewable energy harvesting system using a mechanical vibration rectifier (MVR) for railroads," Applied energy, vol. 204, pp. 1535-1543, 2017.

[18]H. Fu, W. Song, Y. Qin, and E. M. Yeatman, "Broadband vibration energy harvesting from underground trains for self-powered condition monitoring," in 2019 19th International Conference on Micro and Nanotechnology for Power Generation and Energy Conversion Applications (PowerMEMS), 2019: IEEE, pp. 1-5.

\section{CONTACT}

*H. Fu, tel: +44 1509 222514; h.fu@,lboro.ac.uk 